\title{
NOVO METHODO DE TRATAMENTO DA LEHMANIOSE DAS MUCOSAS
}

\section{SERGIO VEIGA DE CARVALHO A NESTOR FIGUEIREDO}

Temos a honra de apresentar ao illustre Congresso Inter-Estadoal de Estudantes de Medicina um novo methodo de tratamento da leihmaniose das mucosas de autoria do Dr Mario Ottoni de Rezende, distincto assistente da Clinica Oto-rhino-laryngologica, a cargo do eminente Prof. H. Lindenberg e sobre o qual o referido autor já apresentou uma nota previa á Sociedade de Medicina Cirurgia de S. Paulo, em sessão ordinaria de 15 de Maio de 1923

A leihmaniose das mucosas tem sido rebelde aos tratamentos conhecidos o tartaro emetico e o tartaro bismuthado, que tĩ $b$ : lhanteg resultados têm dado na cura da leishmaniose tegumentar. mostraram-se até hoje inefficazes no tratamento da localização mucosa; ao contrario a therapeutica que ora apresentamos tem occasionado resultados promissores. Assim é que em casos de leishmaniose ulcero-granulomatosa o methodo preconisado pelo $\mathrm{Dr}$ Mario Ottoni de Rezende tein actuado de tal maneira que os pacientes ficam libertados de tão incommodativa molestia.

Se por um lado é certo que a Sciencia não tem patria, por outro lado não pođemos deixar de nos desvanecer ao lembrarmonos que tanto o tratamento pelo tartaro emetico como o que vamos descrever são obra de dois scientistas brasileiros, respectivamente Gaspar Vianna e Mario Ottoni.

Observando microscopicamente um corte de ulcera leishmaniotica, ella se nos apresenta desprovida de epithelio. Superficialmen te ha uma camada de exsudato leucocytario. No fundo, os tecidos estão intensamente infiltrados por leucocytos, lymphocytos, plasmacellulas e cellulas endotheliaes que têm tendencia a se disporem ao redor de gigantocytos, formando pequenos nodulos. E' possivel distinguir parasitas no cytoplasma das cellulas endotheliaes, sendo, porém, este facto muito raramente observado.

Sendo o nosso fito principal expôr o novo methodo do Dr. Mario Ottoni de Rezende, passamos immediatamente a fazel-o: 
Consiste esse tratamento, segundo o autor, na exerese da mucosa lesada por meio de curetagem e posterior applicação de acido lactico a 80 o|o. A curetagem tem por fim permittir a penetração do acido lactico profundamente nos tecidos doentes, o qual, em solução concentrada não só é ligeiramente caustico como tambem torna os tecidos pouco aptos para o desenvolvimento das raras leishmanias que ahi se encontram. Esse tratamento tem sido praticade na Clinica Oto-rhino-laryngologica da Faculdade de Medicina e Cirurgia de $\mathbf{S}$. Paulo do seguinte modo:

a) Anesthesia da lesão com cocaina a 20 o|o;

b) Curetagem minuciosa de toda a superficie lesada da mucosa e, sobretudo, onde houver granulações;

c) Cauterização de toda a superficie curetada com uma so lução de acido lactico a 80 o|o e assim successivamente;

d) Oito dias depois nova applicação de solução de acido ctico a 80 olo e assim successivamente;

e) Sendo necessario 15 a 20 dias depois da primeira, nova cureth jem óşuida de applicação de acid) lactico.

Esse tratamento deverá ser proseguido até que a mucosa se apresente lisa e completamente cicatrizada.

As vantagens deste novo methodo são innegaveis e nós que tivemos opportunidade de seguir e observar os caso trataajo $_{S}$ por este processo estamos convencidos da sua efficacia, e mai do $_{\mathrm{S}}$ que a nossa modesta opinião fallam as observações que adeante apresentamos:

(Seguem-se as observações).

LABORATORIO DE MICROSC OPIA

$\mathrm{E}$

ANALYSES CLINICAS

DR. ALTINO ANTUNES

RUA DO CARMO N. 11

Teleph. 2463, Central S̃̃ O A ULO 